\title{
Recurrent craniopharyngioma after conformal radiation in children and the burden of treatment
}

\author{
Paul Klimo Jr., MD, MPH, ${ }^{1-3}$ Garrett T. Venable, BS, ${ }^{2}$ Frederick A. Boop, MD, ${ }^{1-3}$ and \\ Thomas E. Merchant, DO, PhD ${ }^{4}$ \\ ${ }^{1}$ Semmes-Murphey Neurologic \& Spine Institute; ${ }^{2}$ Department of Neurosurgery, University of Tennessee Health Science Center; \\ and Departments of ${ }^{3}$ Surgery and ${ }^{4}$ Radiological Sciences, St. Jude Children's Research Hospital, Memphis, Tennessee
}

OBJECT In this paper the authors present their experience treating children with recurrent craniopharyngioma who were initially managed with surgery followed by conformal radiation therapy (CRT).

METHODS A departmental oncology information system was queried to identify all children (< 18 years old) who received CRT for a craniopharyngioma between 1998 and 2010 (inclusive) and specifically those who experienced tumor progression. For each patient, the authors recorded the type of recurrence (solid, cystic, or both), the time interval to first progression and each subsequent progression, the associated treatment complications, and disease status at last follow-up evaluation.

RESULTS Among the 97 patients that met criteria for entry into this study, 18 (18.6\%) experienced tumor progression (9 cystic, 3 solid, 6 cystic and solid). The median time to first recurrence was 4.62 years (range 1.81-9.11 years). The subgroup included 6 female and 12 male patients with a median age of 7.54 years (range 3.61-13.83 years). Ten patients experienced first progression within 5 years of CRT. The 5 - and 10 -year treatment-free survival rates for the entire cohort were $89.0 \%$ (95\% confidence interval [Cl] 80.5\%-93.9\%) and 76.2\% (95\% Cl 64\%-85\%), respectively. Seven patients had a single episode of progression and 11 had more than 1 . The time interval between each subsequent progression was progressively shorter. The 18 patients underwent 38 procedures. The median follow-up duration for this group was 9.32 years (range 4.04-19.0 years). Three patients died, including 1 from perioperative complications.

CONCLUSIONS Craniopharyngioma progression after prior irradiation is exceedingly difficult to treat and local control is challenging despite repeated surgical procedures. Given our results, gross-total resection may need to be the surgical goal at the time of first recurrence, if possible. Decompressing new cyst formation alone has a low rate of long-term success.

http://thejns.org/doi/abs/10.3171/2014.10.PEDS14384

KEY WORDS craniopharyngioma; conformal radiation therapy; tumor progression; oncology

$\mathrm{C}$ RANIOPHARYNGIOMA is a histologically benign tumor that most commonly arises from suprasellar nests of epithelium derived from Rathke's pouch, which is the embryonic precursor of the anterior pituitary gland. The adamantinomatous type predominates in children with solid and cystic components with calcifications, typically in an "egg-shell" pattern. The presenting signs and symptoms are due to involvement of local structures, namely the optic apparatus, hypothalamus, pituitary gland and stalk, and third ventricle. The management of this tumor continues to generate spirited debate among pediatric neurosurgeons, which indicates that there is no preferred treatment paradigm. ${ }^{10}$ Historically, aggressive surgical extirpation has been advocated, with the goal being grosstotal removal. Proponents argue that this approach affords the patient the best chance of a cure without having to endure further potentially harmful treatment, namely additional surgery or radiation. Alternatively, others have advocated conservative or maximal safe resection followed by radiotherapy as a means to provide adequate local tumor control while avoiding the significant morbidity associated with aggressive initial surgery. Two recent pe-

ABBREVIATIONS CI = confidence interval; CRT = conformal radiation therapy; GKS = Gamma Knife surgery; GTR = gross-total resection; IMRT = intensity-modulated radiation therapy; PBT = proton beam therapy; SJCRH = St. Jude Children's Research Hospital; STR = subtotal resection.

SUBMITTED July 25, 2014. ACCEPTED October 31, 2014.

INCLUDE WHEN CITING Published online February 20, 2015; DOI: 10.3171/2014.10.PEDS14384.

DISCLOSURE The authors report no conflict of interest concerning the materials or methods used in this study or the findings specified in this paper. 
diatric systematic reviews demonstrated that there was no difference in the 1- and 5-year progression free survival between the 2 treatment approaches; however, patients treated with gross-total resection (GTR) had a higher risk of developing diabetes insipidus and new neurological deficits. ${ }^{6,7}$ Similar findings were published by Schoenfeld et al. based on a 30-year experience treating both pediatric and adult patients. ${ }^{32}$ Iannalfi et al. performed a literature review covering the period from January 1990 to May 2012 and identified 43 studies including 1716 patients treated with radiation for craniopharyngioma. ${ }^{14}$ From these studies, the reported 10-year local control rates ranged between $77 \%$ and $100 \%$, and the long-term toxicity of combined limited surgery and radiation was less than that associated with radical surgery.

For a number of years, our philosophy at St. Jude Children's Research Hospital (SJCRH) has been to limit the extent of surgical intervention and follow with conformal radiation therapy (CRT). ${ }^{24}$ Initial surgery is tailored to the child's symptoms and the tumor's imaging features. For example, tumors that are causing obstructive hydrocephalus or visual loss as a result of compression of the optic apparatus are often debulked to re-establish CSF pathways or to decompress the visual apparatus, respectively. Tumors that are primarily cystic are often treated by placing a catheter-stereotactically or via craniotomy-into the cyst with immediate decompression, thus reducing the volume needed to be treated with radiation. Aggressive extirpation in an effort to accomplish a GTR is, in general, not pursued, especially if there is hypothalamic involvement noted on the preoperative imaging or at the time of surgery. Injury to the hypothalamus, which is usually due to surgical manipulation as opposed to tumor infiltration as suggested by some, can lead to well-described longterm debilitating complications, such as global loss of neuroendocrine function, uncontrollable appetite, changes in behavior, and cognitive decline. ${ }^{8,35}$ The principal objective for all patients is to minimize surgical morbidity and maximize quality of life by regaining and retaining as much neurological, endocrine, cognitive, and behavioral function for as long as possible.

Surgery is also indicated for tumors that progress after CRT with the focus typically being on the portion of the tumor that demonstrates regrowth. Recurrent craniopharyngioma in children is one of the most difficult challenges faced by pediatric neurosurgeons. Treatments following CRT are broadly divided into more surgery or stereotactic radiosurgery; further CRT is not an option. This report details our experience in treating children who have demonstrated either cystic or solid tumor progression following photon-based CRT.

\section{Methods \\ Study Population}

Using a prospectively maintained database, we identified all children ( $<18$ years old) who underwent CRT for a craniopharyngioma (with or without tissue confirmation) between 1998 and 2010 (inclusive) at SJCRH. Many of these patients were part of a previous SJCRH prospective observational trial. ${ }^{23}$ Eligible patients were those who had undergone preradiation surgery of any kind performed at Le Bonheur Children's Hospital or at an outside institution, but with radiation and follow-up visits at SJCRH. We stopped adding new patients beyond 2010 so that we could have at least 3.5 years of follow-up for each patient. From this group, we identified patients who developed solid and/or cystic recurrence or progression of residual tumor 1 year or more after CRT. Recurrence was defined as any new tumor in a patient who underwent a GTR or progression of previously radiologically stable residual tumor. For each recurrence, we recorded the type (solid, cystic, or both), the date and the method of subsequent surgical or radiosurgical treatment, and any treatment-related complications. The institutional review board at SJCRH approved this study.

\section{Definitions}

Time to first recurrence was defined as the number of days from the start of radiation to the date of surgical intervention for the recurrence (treatment-free survival). Time to subsequent recurrence was the number of days between treatments. Total follow-up duration was the number of days from the date of diagnosis to the last clinic follow-up evaluation, or death. At last follow-up, we classified patients as having either stable or progressive disease based on their last MRI examination. It should be noted that the presence of radiographic progressive disease does not mean that the patient has undergone treatment for its recurrence. Patients who had a GTR with no evidence of regrowth at last follow-up were still labeled as stable disease rather than as disease free.

\section{Imaging and Radiation Treatment Planning}

A CT scan and contrast-enhanced MR image was obtained approximately 1 week before the start of CRT. The gross tumor volume for the baseline plan was contoured on the T2-weighted MR image supplemented by the T1 contrast-enhanced sequence and the CT scan. The clinical and planning target volume margins used for treatment planning were $5 \mathrm{~mm}$ and $3 \mathrm{~mm}$, respectively. The total radiation dose was $54 \mathrm{~Gy}$, given in $1.8 \mathrm{~Gy}$ fractions, 5 days per week, over a total of 6 weeks. MRI was performed during treatment with a frequency determined by protocol or physician preference. ${ }^{25}$

\section{Results}

Ninety-seven pediatric patients (52 boys and 45 girls) completed photon CRT during the time interval 19982010. The median age at the time of CRT was 8.94 years (range 3.2-17.64 years).

\section{Treatment-Free Survival and Time to Subsequent Progression}

Among the 97 patients, 18 (18.6\%) experienced tumor progression. Table 1 details the characteristics of the 18 patients with tumor progression. There were 6 girls and 12 boys with a median age of 7.54 years (range 3.61-13.83 years) at the time that their recurrent tumor was treated. The median time to treatment for tumor progression was 
TABLE 1. Characteristics of 18 patients with craniopharyngiomas and failed CRT

\begin{tabular}{|c|c|c|c|c|c|c|c|}
\hline $\begin{array}{l}\text { Case } \\
\text { No. }\end{array}$ & $\begin{array}{l}\text { Age at } \\
\text { Dx (yrs) } \\
\text { Sex }\end{array}$ & $\begin{array}{l}\text { Initial } \\
\text { Surgical } \\
\text { Treatment }\end{array}$ & $\begin{array}{l}\text { Time to 1st } \\
\text { Recurrence } \\
\text { (days) }^{*}\end{array}$ & $\begin{array}{l}\text { Recurrence } \\
\text { Type }\end{array}$ & Treatment & $\begin{array}{c}\text { Subsequent Recurrences (days)†/ } \\
\text { Type/Treatment }\end{array}$ & Status at Last Follow-Up \\
\hline 1 & $5.9, \mathrm{M}$ & STR & 1381 & Cystic & Ommaya-s w/ bleomycin & 738/cystic/Ommaya revision-s & Deceased/stable disease \\
\hline 2 & $6.8, M$ & STR & 1052 & Both & STR & $\begin{array}{l}\text { 1: 219/solid/STR \& } 28 \text { days later GKS } \\
\text { 2: } 1815 / \text { cystic/GTR } \\
\text { 3: 532/cystic/GTR }\end{array}$ & Progressive disease \\
\hline 3 & 13.6, M & STR & 1476 & Both & GTR & None & Deceased \\
\hline 4 & $9, M$ & Ommaya-s & 1628 & Solid & GTR & None & Stable disease \\
\hline 5 & $4, \mathrm{~F}$ & Biopsy & 3324 & Both & $\begin{array}{l}\text { Endoscopic fenestration } \\
\text { \& Ommaya-s }\end{array}$ & 672/solid/STR & Deceased/stable disease \\
\hline 6 & $5.5, F$ & Ommaya-s & 2253 & Solid & GTR & None & Stable disease \\
\hline 7 & 7.7, M & Biopsy & 663 & Both & STR & 298/solid/GTR & Stable disease \\
\hline 8 & $8, M$ & Ommaya-s & 1880 & Cystic & Ommaya-o & None & Progressive disease \\
\hline 9 & $4.8, M$ & STR & 2140 & Cystic & GTR & $\begin{array}{l}\text { 1: 2959/cystic/GTR } \\
\text { 2: 295/cystic/GTR }\end{array}$ & Stable disease \\
\hline 10 & $6.3, \mathrm{M}$ & STR & 1745 & Cystic & STR & 1056/cystic/STR & Stable disease \\
\hline 11 & $5.5, \mathrm{M}$ & STR & 969 & Cystic & Ommaya-s & $\begin{array}{l}\text { 1: 802/both/GTR } \\
\text { 2: 326/cystic/Ommaya-o } \\
\text { 3: 79/cystic/STR }\end{array}$ & Stable disease \\
\hline 12 & 3.6, M & STR & 1387 & Cystic & Ommaya-s & None & Stable disease \\
\hline 13 & $12, \mathrm{~F}$ & Biopsy & 1557 & Cystic & Ommaya-s & 1670/cystic/STR & Progressive disease \\
\hline 14 & $3.3, F$ & STR & 2147 & Both & STR & $\begin{array}{l}\text { 1: } 670 / \text { cystic/STR } \\
\text { 2: } 344 / \text { cystic/Ommaya-s attempted } \\
\text { but failed, then STR } 5 \text { days later }\end{array}$ & Progressive disease \\
\hline 15 & $3.9, \mathrm{M}$ & STR & 1835 & Both & STR & 214/cystic/STR \& 28 days later GKS & Stable disease \\
\hline 16 & $9.4, \mathrm{~F}$ & Biopsy & 2199 & Cystic & $\begin{array}{l}\text { Transsphenoidal cyst } \\
\text { fenestration }\end{array}$ & 177/cystic/STR & Progressive disease \\
\hline 17 & $3.5, \mathrm{M}$ & None & 3119 & Solid & GTR & None & Stable disease \\
\hline 18 & $8.2, F$ & STR & 1047 & Cystic & Transsphenoidal STR & None & Stable disease \\
\hline
\end{tabular}

4.62 years (range 1.81-9.11 years). The 5- and 10-year treatment-free survival rates were $89.0 \%$ (95\% confidence interval [CI] $80.5 \%-93.9 \%$ ) and $76.3 \%$ (95\% CI 64\%$85 \%$ ), respectively. In 10 patients $(56 \%)$, tumor progression requiring treatment occurred within 5 years of CRT.

The pattern of progression was cystic in 9 cases, solid in 3 , and both cystic and solid in 6 . There was no statistically significant difference in time to recurrence comparing patients based on progression pattern. Seven patients had a single recurrence, 7 had 2 recurrences, 2 had 3 recurrences, and 2 had 4 recurrences. The time interval between each treatment for a new recurrence was progressively shorter. The median and mean times to treatment of first recurrence, between first and second, second and third, and third and fourth, were respectively 1687 and 1767 days (range 663-3324 days), 672 and 861 days (range 177-2959 days), 335 and 695 days (range 295-1815 days), and 306 and 306 days (range 79-532 days), respectively.

\section{Treatment for Progression}

As shown in Fig. 1 and Table 1, these 18 patients un- derwent a total of 38 procedures after CRT for recurrent disease: craniotomy (including GTR and subtotal resection [STR], $\mathrm{n}=27$ ), bur hole for stereotactic placement of an Ommaya reservoir $(\mathrm{n}=7)$, transsphenoidal surgery ( $\mathrm{n}$ $=2$ ), and Gamma Knife surgery $(\mathrm{GKS} ; \mathrm{n}=2)$. Of those with a cyst as the first recurrence $(n=9), 5$ were initially treated with placement of an Ommaya catheter (either via craniotomy or stereotactic bur hole), 2 had STR of their entire tumor burden, 1 had a GTR, and 1 had a transsphenoidal cyst fenestration. Among those with cystic recurrence, 6 patients $(67 \%)$ subsequently developed another recurrence, and at last follow-up 3 had progressive disease and 6 had stable disease, including 1 patient who died 7.6 years after diagnosis. The 6 patients who developed both solid and cystic first-time progression were treated initially with STR $(\mathrm{n}=4)$, GTR $(\mathrm{n}=1)$, and an Ommaya catheter $(n=1)$. All but 1 of these patients $(83 \%)$ developed another recurrence requiring further treatment, and at last follow-up 2 had progressive disease, 2 had stable disease, and 2 had died at 4.1 and 13.1 years after diagnosis. One of these children died with stable disease and the other died 


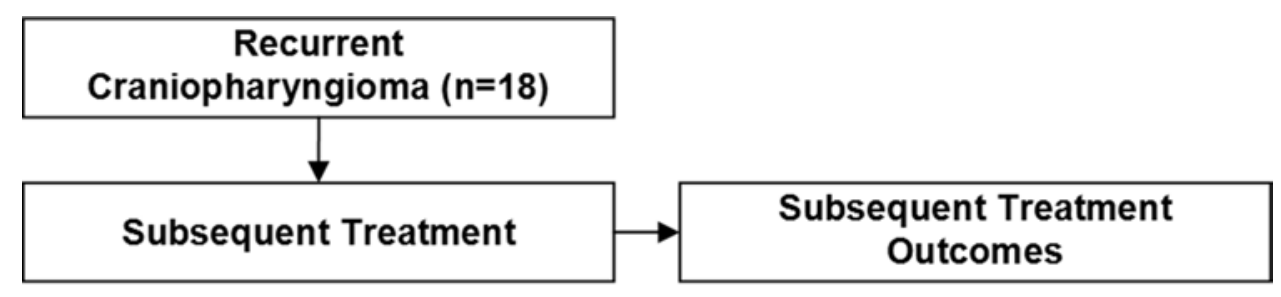

\section{Solid Recurrence}

\begin{tabular}{|l|l|l|}
\hline $\begin{array}{l}3 \text { patients experienced solid } \\
\text { recurrence }\end{array}$ & $\rightarrow \begin{array}{l}\bullet 0 \text { patients experienced } \\
\text { recurrence } \\
\bullet \text { All patients had SD at last F/U }\end{array}$ \\
\cline { 2 - 3 }
\end{tabular}

\section{Cystic Recurrence}

\begin{tabular}{|c|c|}
\hline $\begin{array}{l}9 \text { patients experienced cystic } \\
\text { recurrence } \\
\text { - } 5 \text { treated with Ommaya } \\
\text { placement } \\
\text { - } 2 \text { treated with STR } \\
\text { - } 1 \text { treated with GTR } \\
\text { - } 1 \text { treated with Cyst Fenestration }\end{array}$ & $\begin{array}{l}\text { - Ommaya: } 5 \text { total recurrences, } 2 \\
\text { patients with } 0 \text { recurrences. } 2 \\
\text { SD, } 2 \text { PD, } 1 \text { Death } \\
\text { - STR: } 1 \text { recurrence; } 1 \text { patient with } \\
\text { O recurrences; both with SD } \\
\text { - GTR: } 2 \text { recurrences; patient with } \\
\text { SD } \\
\text { - Cyst Fenestration: } 1 \text { recurrence; } \\
\text { patient with PD }\end{array}$ \\
\hline
\end{tabular}

\section{Solid/Cystic Recurrence}

\begin{tabular}{|c|c|}
\hline $\begin{array}{l}6 \text { patients experienced solid/ } \\
\text { cystic recurrence } \\
\cdot 4 \text { treated with STR } \\
\cdot 1 \text { treated with GTR } \\
\cdot 1 \text { treated with Cyst Fenestration }\end{array}$ & $\begin{array}{l}\text { - STR: } 7 \text { total recurrences; no } \\
\text { patients had } 0 \text { recurrences; } 2 \\
\text { with SD, } 2 \text { with PD } \\
\text { - GTR: } 0 \text { recurrences; } 1 \text { death } \\
\text { - Cyst Fenestration: } 1 \text { recurrence; } \\
1 \text { death }\end{array}$ \\
\hline
\end{tabular}

FIG. 1. Treatment summary for the 18 patients who developed recurrent tumor after $C R T$. F/U = follow-up; $P D=$ progressive disease; $\mathrm{SD}=$ stable disease.

shortly after surgery (see Morbidity and Mortality). All 3 patients with a solid first-time recurrence went on to undergo GTR, have not required any further treatment, and have stable disease at the last follow-up evaluation.

In 8 patients, GTR was achieved 11 times, including 5 times for the first recurrence. In 1 patient (Case 3 ), the effectiveness of resection could not be assessed because he died shortly after surgery (see Morbidity and Mortality). Of the 4 patients alive at last follow-up who underwent GTR for their first recurrence, 3 of them have not had further recurrences and have radiologically stable disease at last follow-up.

\section{Morbidity and Mortality}

There were 13 notable treatment-related complications that occurred in 9 patients. Six patients developed diabetes insipidus after surgery, 2 of whom also experienced a seizure in the postoperative period as a result of serum sodium fluctuations, and 1 patient also developed hypocortisolemia. Two patients suffered a partial loss of vision after resection. One patient suffered lower cranial neuropathies as a result of bleomycin leakage out of his tumor cyst (this patient was treated early in our series and is the only one treated with intracystic bleomycin). The final complication was radiation-induced vasculopathy requiring bypass surgery 2.5 years after completion of CRT. Three of 18 patients have died; 2 of these deaths were due to sepsis unrelated to any recent surgical procedure or shunt infection. The third death occurred in a 17-year-old boy who 4 years previously had undergone CRT and then developed a solid and cystic recurrence (Case 3 ). After undergoing a GTR, the patient's postoperative course was complicated by, in chronological order, severe hypertension requiring continuous antihypertensive infusion, hemiparesis with a CT scan that demonstrated diffuse bilateral cerebral edema, an anterior myocardial infarction, extreme fever $\left(110^{\circ} \mathrm{F}\right)$, myoglobinuria, renal failure, and ultimately brain death 5 days after surgery. It is unclear what led to these events, but uncorrected preoperative endocrinopathy was believed to have been a significant factor; an autopsy was not performed. 


\section{Overall Survival}

The median follow-up duration for the entire cohort $(\mathrm{n}=97$ ) was 9 years (range $0.7-19.0$ years). The median follow-up duration for the cohort that experienced progression $(\mathrm{n}=18$ ) was 9.32 years (range $4.04-19.0$ years). A total of 7 patients have died. Four died of complications related to the tumor and treatment without evidence of progression (i.e., opportunistic infection, vasculopathy, and secondary malignancy), including the first patient in the cohort. As discussed in the previous section, 3 of the patients in the progression cohort died. The overall 5- and 10-year survival rates for all 97 patients were $98.9 \%(95 \%$ CI $92.4 \%-99.8 \%$ ) and $94.5 \%$ (95\% CI $85.9 \%-98.0 \%$ ), respectively. Among the patients who have not experienced progression, the 5- and 10-year survival rates were $100 \%$ and $96.3 \%$ (95\% CI 85.4\%-99.1\%), respectively; for those who experienced tumor progression, the rates were $94.1 \%$ (95\% CI 65\%-99.2\%) and 87.8\% (95\% CI 59.5\%-96.8\%), respectively.

\section{Discussion}

Conformal radiation therapy following maximal safe resection or decompression of a predominantly cystic tumor has been our general approach for children with craniopharyngiomas as a way to maximize local control and minimize surgical morbidity. In this study we report our experience with a cohort of 18 patients who failed CRT. Of the original group of 97 patients, almost 20\% went on to develop tumor recurrence with a median and mean time to first recurrence of 4.6 and 4.8 years, respectively, and the 5- and 10-year treatment free-survival rates were $89 \%$ and $76 \%$, respectively. Eleven of the 18 patients developed 1 or more subsequent recurrences, with the time interval between treatments for each recurrence becoming progressively shorter. Collectively, 38 procedures directed at the recurrence were performed or attempted. Do these statistics suggest that recurrent craniopharyngioma is a more biologically aggressive tumor than its original form? Unlike the work that is currently being performed to unlock the molecular mysteries of both the de novo and recurrent forms of other pediatric tumors, notably medulloblastoma ${ }^{30}$ such work has yet to be performed with craniopharyngioma. In a recent article, Prieto et al. reviewed the literature and found features of a craniopharyngioma that were related to a higher risk of recurrence included larger tumor size, tight adherence to the hypothalamus, the presence of whorl-like arrays, and high levels of Ki 67, p53, epithelial cell adhesion molecule, and pituitary tumor transforming gene. ${ }^{29,34}$ To this list, others have unequivocally demonstrated that patients with an STR without adjuvant CRT are at high risk of recurrence. ${ }^{7,20,32}$

A number of groups have reported their experience with recurrent craniopharyngiomas, but direct comparison between our results and theirs is limited because of different treatment preferences, follow-up times, or the inclusion of adults. Jang et al. performed 32 operations in 7 pediatric patients, 4 of whom received CRT after their first surgery and 2 patients after their second. ${ }^{15}$ Like our study, they demonstrated that the interval between each surgery became shorter, and the median time to first re- currence in their patients was almost identical to the one in our series (58 vs 55.4 months, respectively). Bishop et al. recently published results from 2 institutions. ${ }^{3}$ Fiftytwo children were treated with either intensity-modulated radiation therapy (IMRT; $\mathrm{n}=31$ ) or proton beam therapy (PBT; $\mathrm{n}=21$ ) with a median follow-up of 59.6 months for the entire cohort, but 106 months for the patients treated with IMRT, similar to our patient population (9 years). Of their 31 patients who underwent IMRT, 3 (10\%) developed a cystic recurrence requiring surgical intervention and 1 a nodular recurrence 24 months after IMRT, but they do not indicate whether this patient required surgery. Thus, their overall recurrence rate and treatment burden were both significantly less than our series.

In 2010, Elliott et al. published Dr. Wisoff's personal series of 86 children with craniopharyngiomas over a 22-year period. ${ }^{11}$ Their treatment philosophy differs significantly from ours in that they have been staunch advocates of GTR in virtually all patients without adjuvant CRT. Their overall recurrence rate $(22 \%)$ was similar to ours (18.6\%), including a $20 \%$ rate for the 71 patients who underwent a GTR. The median time to recurrence in patients who had a GTR was much shorter $(20$ months, range 1-123 months) and all recurrences except 1 developed within 48 months of surgery. For those who had an STR, the median time to progression was even shorter at 3.5 months. Finally, as with our study, they also found that the time to subsequent recurrence was shorter in patients who had already developed a recurrence compared with those who did not. Minamida et al. reported their results in a series of 11 patients with recurrent tumors, 5 of whom were less than 18 years of age. ${ }^{26}$ Their overall recurrence rate was $30 \%$ and the median time from first surgery to recurrence was 6.2 years. These 11 patients underwent 17 operations for recurrences, and none received radiation.

With only 18 patients with recurrent disease in our series, including 1 who died shortly after surgery for his first-time recurrence, it is difficult to make any robust treatment recommendations. Our patients who underwent GTR after their first recurrence appeared to have a lower risk of subsequent recurrence. Until now, we have been guided by two principles when faced with recurrent disease. We continue to believe that tumor that is adherent to critical neurovascular structures should not be excessively tampered with or manipulated for fear of causing irreversible neurological morbidity. The second principle was to resect only that portion of the tumor that has progressed after CRT. Given our results showing the high burden of treatments in those that recur after radiation, maximal safe resection of all disease may be the optimal surgical strategy at first recurrence, which will hopefully translate into a greater chance of long-term local tumor control, a position that is shared by others. ${ }^{9}$ Placing a catheter for cystic recurrence is unlikely to afford any long-term control, as only 1 patient in our series who underwent this procedure has not developed further tumor regrowth or radiological progressive disease at last follow-up. For those patients in whom complete resection cannot be safely accomplished, the use of stereotactic radiosurgery directed at the residual may be considered as it has been repeatedly demonstrated to be safe and effective. ${ }^{16-18,27,36,38}$ 
Contrary to the view of other authors, ${ }^{26,35}$ surgery for recurrent disease is difficult and risky. In general, each ensuing surgery becomes progressively more demanding due to fibrosis and loss of the natural pial-arachnoid tissue planes that surround normal neurovascular structures and the tumor as a result of prior surgery, and to a lesser degree radiation, not to mention the intrinsic characteristics of the tumor itself (e.g., calcifications). Elliott et al. demonstrated that prior radiation and recurrent disease negatively impacted the surgeon's ability to achieve a complete resection. ${ }^{11}$ Newer surgical techniques and technology, such as endoscopy/transsphenoidal surgery, ${ }^{4,19,37}$ supraorbital eyebrow craniotomy, ${ }^{22}$ and intraoperative MRI surgery ${ }^{1,5}$ may lead to better surgical results with less morbidity. Unfortunately, the reality is that a significant percentage of children with recurrent postradiation craniopharyngioma will not be cured and will suffer from treatment-related complications or toxicity.

Lastly, PBT as the initial form of CRT, as opposed to conventional photon IMRT, may provide better local control rates at reduced levels of whole-brain and body irradiation. ${ }^{2,21}$ Fitzek et al. treated 5 children with a median dose prescribed to the tumor of 56.9 cobalt Gray equivalents and a median follow-up of 13.1 years..$^{13}$ None of these 5 patients experienced tumor recurrence. Bishop et al. ${ }^{3}$ demonstrated no superiority of PBT over IMRT with regards to survival and disease-control (cystic and nodular recurrence) outcomes. PBT is currently available in few centers and its use in children with craniopharyngioma is still in its early stages.

Our study has a number of limitations, some of which have already been mentioned. Our patient series is small and our findings are generalizable to those institutions that similarly prescribe adjuvant CRT in all of their pediatric patients. Because any one institution will have only a handful of these cases, multicenter efforts-and even international collaborative efforts-are necessary to properly develop treatment algorithms. ${ }^{33}$ Our end points were limited and we did not have quality of life data, an important outcome to measure in this population that the disease and treatments directly impact. ${ }^{12,28,31}$

\section{Conclusions}

The management of recurrent craniopharyngioma in children is extremely challenging. The overall rate of recurrence in children with craniopharyngioma treated at our institution using photon CRT was nearly $20 \%$. Just over half of our patients required treatment for their first progression during the first 5 years after CRT. Eleven children developed more than 1 recurrence necessitating a high treatment burden. All available surgical tactics should be used to maximally resect the recurrent tumor without jeopardizing neurological, behavioral, and cognitive function. Stereotactic radiosurgery may be considered for any residual tumor after such resection. These patients require multidisciplinary long-term follow-up.

\section{Acknowledgment}

We wish to thank Andrew J. Gienapp for technical editing and copyediting, preparation of the manuscript and figures for publication, and publication assistance with this manuscript.

\section{References}

1. Avula S, Pettorini B, Abernethy L, Pizer B, Williams D, Mallucci C: High field strength magnetic resonance imaging in paediatric brain tumour surgery-its role in prevention of early repeat resections. Childs Nerv Syst 29:1843-1850, 2013

2. Beltran C, Roca M, Merchant TE: On the benefits and risks of proton therapy in pediatric craniopharyngioma. Int J Radiat Oncol Biol Phys 82:e281-e287, 2012

3. Bishop AJ, Greenfield B, Mahajan A, Paulino AC, Okcu MF, Allen PK, et al: Proton beam therapy versus conformal photon radiation therapy for childhood craniopharyngioma: multi-institutional analysis of outcomes, cyst dynamics, and toxicity. Int J Radiat Oncol Biol Phys 90:354-361, 2014

4. Cavallo LM, Prevedello DM, Solari D, Gardner PA, Esposito F, Snyderman CH, et al: Extended endoscopic endonasal transsphenoidal approach for residual or recurrent craniopharyngiomas. J Neurosurg 111:578-589, 2009

5. Choudhri AF, Klimo P Jr, Auschwitz TS, Whitehead MT, Boop FA: 3T intraoperative MRI for management of pediatric CNS neoplasms. AJNR Am J Neuroradiol 35:23822387, 2014

6. Clark AJ, Cage TA, Aranda D, Parsa AT, Auguste KI, Gupta $\mathrm{N}$ : Treatment-related morbidity and the management of pediatric craniopharyngioma. A systematic review. J Neurosurg Pediatr 10:293-301, 2012

7. Clark AJ, Cage TA, Aranda D, Parsa AT, Sun PP, Auguste $\mathrm{KI}$, et al: A systematic review of the results of surgery and radiotherapy on tumor control for pediatric craniopharyngioma. Childs Nerv Syst 29:231-238, 2013

8. De Vile CJ, Grant DB, Kendall BE, Neville BG, Stanhope R, Watkins KE, et al: Management of childhood craniopharyngioma: can the morbidity of radical surgery be predicted? $\mathbf{J}$ Neurosurg 85:73-81, 1996

9. Di Rocco C, Caldarelli M, Tamburrini G, Massimi L: Surgical management of craniopharyngiomas-experience with a pediatric series. J Pediatr Endocrinol Metab 19 (Suppl 1):355-366, 2006

10. DiPatri AJ Jr, Prabhu V: A history of the treatment of craniopharyngiomas. Childs Nerv Syst 21:606-621, 2005

11. Elliott RE, Hsieh K, Hochm T, Belitskaya-Levy I, Wisoff J, Wisoff JH: Efficacy and safety of radical resection of primary and recurrent craniopharyngiomas in 86 children. J Neurosurg Pediatr 5:30-48, 2010

12. Elliott RE, Sands SA, Strom RG, Wisoff JH: Craniopharyngioma Clinical Status Scale: a standardized metric of preoperative function and posttreatment outcome. Neurosurg Focus 28(4):E2, 2010

13. Fitzek MM, Linggood RM, Adams J, Munzenrider JE: Combined proton and photon irradiation for craniopharyngioma: long-term results of the early cohort of patients treated at Harvard Cyclotron Laboratory and Massachusetts General Hospital. Int J Radiat Oncol Biol Phys 64:1348-1354, 2006

14. Iannalfi A, Fragkandrea I, Brock J, Saran F: Radiotherapy in craniopharyngiomas. Clin Oncol (R Coll Radiol) 25:654667, 2013

15. Jang WY, Lee KS, Son BC, Jeun SS, Hong YK, Lee SW, et al: Repeat operations in pediatric patients with recurrent craniopharyngiomas. Pediatr Neurosurg 45:451-455, 2009

16. Jeon C, Kim S, Shin HJ, Nam DH, Lee JI, Park K, et al: The therapeutic efficacy of fractionated radiotherapy and gammaknife radiosurgery for craniopharyngiomas. J Clin Neurosci 18:1621-1625, 2011

17. Kobayashi T, Kida Y, Mori Y, Hasegawa T: Long-term results of gamma knife surgery for the treatment of craniopharyngioma in 98 consecutive cases. J Neurosurg 103 (6 Suppl):482-488, 2005

18. Lee M, Kalani MY, Cheshier S, Gibbs IC, Adler JR, Chang SD: Radiation therapy and CyberKnife radiosurgery in the 
management of craniopharyngiomas. Neurosurg Focus 24(5):E4, 2008

19. Leng LZ, Greenfield JP, Souweidane MM, Anand VK, Schwartz TH: Endoscopic, endonasal resection of craniopharyngiomas: analysis of outcome including extent of resection, cerebrospinal fluid leak, return to preoperative productivity, and body mass index. Neurosurgery 70:110-124, 2012

20. Liubinas SV, Munshey AS, Kaye AH: Management of recurrent craniopharyngioma. J Clin Neurosci 18:451-457, 2011

21. Luu QT, Loredo LN, Archambeau JO, Yonemoto LT, Slater JM, Slater JD: Fractionated proton radiation treatment for pediatric craniopharyngioma: preliminary report. Cancer J 12:155-159, 2006

22. McLaughlin N, Ditzel Filho LF, Shahlaie K, Solari D, Kassam AB, Kelly DF: The supraorbital approach for recurrent or residual suprasellar tumors. Minim Invasive Neurosurg 54:155-161, 2011

23. Merchant TE, Kiehna EN, Kun LE, Mulhern RK, Li C, Xiong X, et al: Phase II trial of conformal radiation therapy for pediatric patients with craniopharyngioma and correlation of surgical factors and radiation dosimetry with change in cognitive function. J Neurosurg 104 (2 Suppl):94-102, 2006

24. Merchant TE, Kiehna EN, Sanford RA, Mulhern RK, Thompson SJ, Wilson MW, et al: Craniopharyngioma: the St. Jude Children's Research Hospital experience 1984-2001. Int J Radiat Oncol Biol Phys 53:533-542, 2002

25. Merchant TE, Kun LE, Hua CH, Wu S, Xiong X, Sanford RA, et al: Disease control after reduced volume conformal and intensity modulated radiation therapy for childhood craniopharyngioma. Int J Radiat Oncol Biol Phys 85:e187e192, 2013

26. Minamida Y, Mikami T, Hashi K, Houkin K: Surgical management of the recurrence and regrowth of craniopharyngiomas. J Neurosurg 103:224-232, 2005

27. Niranjan A, Kano H, Mathieu D, Kondziolka D, Flickinger JC, Lunsford LD: Radiosurgery for craniopharyngioma. Int J Radiat Oncol Biol Phys 78:64-71, 2010

28. Poretti A, Grotzer MA, Ribi K, Schönle E, Boltshauser E: Outcome of craniopharyngioma in children: long-term complications and quality of life. Dev Med Child Neurol 46:220-229, 2004

29. Prieto R, Pascual JM, Subhi-Issa I, Jorquera M, Yus M, Martínez R: Predictive factors for craniopharyngioma recurrence: a systematic review and illustrative case report of a rapid recurrence. World Neurosurg 79:733-749, 2013

30. Ramaswamy V, Remke M, Bouffet E, Faria CC, Perreault S, Cho YJ, et al: Recurrence patterns across medulloblastoma subgroups: an integrated clinical and molecular analysis. Lancet Oncol 14:1200-1207, 2013
31. Sands SA, Milner JS, Goldberg J, Mukhi V, Moliterno JA, Maxfield C, et al: Quality of life and behavioral follow-up study of pediatric survivors of craniopharyngioma. J Neurosurg 103 (4 Suppl):302-311, 2005

32. Schoenfeld A, Pekmezci M, Barnes MJ, Tihan T, Gupta N, Lamborn KR, et al: The superiority of conservative resection and adjuvant radiation for craniopharyngiomas. J Neurooncol 108:133-139, 2012

33. Spoudeas HA, Saran F, Pizer B: A multimodality approach to the treatment of craniopharyngiomas avoiding hypothalamic morbidity: a UK perspective. J Pediatr Endocrinol Metab 19 (Suppl 1):447-451, 2006

34. Tena-Suck ML, Ortiz-Plata A, Galán F, Sánchez A: Expression of epithelial cell adhesion molecule and pituitary tumor transforming gene in adamantinomatous craniopharyngioma and its correlation with recurrence of the tumor. Ann Diagn Pathol 13:82-88, 2009

35. Vinchon M, Dhellemmes P: Craniopharyngiomas in children: recurrence, reoperation and outcome. Childs Nerv Syst 24:211-217, 2008

36. Xu Z, Yen CP, Schlesinger D, Sheehan J: Outcomes of Gamma Knife surgery for craniopharyngiomas. J Neurooncol 104:305-313, 2011

37. Yamada S, Fukuhara N, Oyama K, Takeshita A, Takeuchi Y, Ito J, et al: Surgical outcome in 90 patients with craniopharyngioma: an evaluation of transsphenoidal surgery. World Neurosurg 74:320-330, 2010

38. Yomo S, Hayashi M, Chernov M, Tamura N, Izawa M, Okada Y, et al: Stereotactic radiosurgery of residual or recurrent craniopharyngioma: new treatment concept using Leksell gamma knife model $\mathrm{C}$ with automatic positioning system. Stereotact Funct Neurosurg 87:360-367, 2009

\section{Author Contributions}

Conception and design: Klimo. Acquisition of data: Klimo, Venable, Merchant. Analysis and interpretation of data: Klimo, Venable, Merchant. Drafting the article: Klimo. Critically revising the article: all authors. Reviewed submitted version of manuscript: all authors. Approved the final version of the manuscript on behalf of all authors: Klimo. Statistical analysis: Klimo, Venable. Study supervision: Klimo.

\section{Correspondence}

Paul Klimo Jr., Semmes-Murphey Neurologic \& Spine Institute, 6325 Humphreys Blvd., Memphis, TN 38120. email: pklimo@ semmes-murphey.com. 